\title{
The Intimate Partner Violence experiences of sexual assault, a risk factor on the transmission of HIV infection among women in the Vhembe District of Limpopo Province, South Africa
}

\section{Fikile C. Madzimbalale ${ }^{1}$, Lunic B. Khoza ${ }^{2}$, Rachel T. Lebese ${ }^{3 *}$ and Hilda N. Shilubane ${ }^{4}$}

${ }^{1}$ Magister Curationis Student, University of Venda, South Africa

${ }^{2}$ Doctor of Literature and Philosophy (UNISA), South Africa

${ }^{3}$ Doctor Curationis, University of Venda, South Africa

${ }^{4}$ Masters Curationis (UNISA), South Africa

\begin{abstract}
Violence against women is present in every country and it cut across boundaries of culture, class, education, income, ethnicity and age. Research has shown that there are links between HIV and AIDS, gender inequity and gender based violence that prevents women from influencing the circumstances of sex, resulting in unsafe sex practice and contracting of sexually transmitted infections including HIV and AIDS.

The overall objective of the study was to increase understanding of Intimate Partner Violence experiences of sexual assault, its risk factor on the transmission of HIV infection among women admitted in Trauma Unit A of a particular hospital in the Vhembe District. This raises the questions "What is the women's experience of sexual assault? Is sexual assault a risk factor to the transmission of HIV infection among women?"

The research design was qualitative, exploratory descriptive and contextual in nature. In this study the target population consisted of all women who made use of a trauma unit A ata particular hospital in the LimpopoProvince. Six participants were selected by means of purposive sampling. In-depth individual interviews were conducted, using a voice recorder.

The principles outlined by Lincoln and Guba were followed to ensure the trustworthiness of the study. Data analysis was guided by Tesch's principles of qualitative data analysis.

The findings of the study reflected that women experienced Intimate Partner Violence sexual assault in their lives and that sexual assault is a risk factor to the transmission of HIV infection among women. The study therefore, suggests a need for screening and prevention programmes that aims to reduce Intimate Partner Violence and HIV infection.
\end{abstract}

\section{Introduction}

Violence and human immunodeficiency virus (HIV) have been reported to be the critical health problems affecting the lives of millions of women regardless of age, culture or socioeconomic status [1]. HIV positive women report high rates of Intimate Partner Violence (IPV) and there is evidence that traumatic experiences have a negative impact on health [2-4]. At least 1 in every 3 women around the world has been beaten, abused, or coerced into sex during her lifetime. In the United States of America (USA), approximately $12 \%$ of HIV/AIDS infections among women in romantic relationships are due to IPV [3].

It is documented that countries are increasingly adopting legislative provisions that address violence against women and children. Laws on domestic violence, marital rape, trafficking in human beings and others have been implemented in many nations including South Africa $[5,6]$.

The domestic Violence Act (Act no. 116 of 1998) [7] was introduced in South Africa with the aim of affording women protection from physical, psychological, economical, social, and sexual harm, by creating the obligation for law enforcement bodies to protect women as far as possible. The Act sets out a broad range of behaviours that constitute domestic violence, including physical, sexual, verbal, emotional and psychological abuse, stalking, intimidation, harassment, malicious damage to property, unauthorised access to the complainants' property, as well as other forms of controlling behaviour which may cause harm to the safety, health or wellbeing of the complainant. This is supported by the constitution of the Republic of South Africa Act (Act no. 108 of
1996) [8] which states that everyone has the right to equality, freedom and security. According to Goosen \& Klugman [9] the Domestic Violence Act (Act 116 of 1998) [8] does not give women enough protection, as sometimes men do not honour the protection order. Women are still abused after the issuing of a protection order. Victims of violence often do not talk about their experiences particularly when the act is related to sexual assault. A woman who is sexually abused may be too embarrassed and humiliated to speak out. It has been observed globally that failure to bring perpetrators to justice is also a major hurdle in tackling violent crimes. For example in England, only one out of 19 men accused of rape will ever be convicted [5].

In 1996 the World Health Assembly declared violence to be a public

*Corresponding author: Rachel T. Lebese, Doctor Curationis, University of Venda Advanced Nursing Science, University road, Thohoyandou, Limpopo, South Africa, Tel: 27 715618263; Fax: 0866190062; E-mail: Rachel.Lebese@univen.ac.za

Received October 19, 2011; Accepted December 02, 2011; Published Decembe 05, 2011

Citation: Madzimbalale FC, Khoza LB, Lebese RT, Shilubane HN (2011) The Intimate Partner Violence experiences of sexual assault, a risk factor on the transmission of HIV infection among women in the Vhembe District of Limpopo Province, South Africa. J AIDS Clinic Res 2:130. doi:10.4172/2155-6113.1000130

Copyright: (c) 2011 Madzimbalale FC, et al. This is an open-access article distributed under the terms of the Creative Commons Attribution License, which permits unrestricted use, distribution, and reproduction in any medium, provided the original author and source are credited. 
Citation: Madzimbalale FC, Khoza LB, Lebese RT, Shilubane HN (2011) The Intimate Partner Violence experiences of sexual assault, a risk factor on the transmission of HIV infection among women in the Vhembe District of Limpopo Province, South Africa. J AIDS Clinic Res 2:130. doi:10.4172/2155-6113.1000130

Page 2 of 6

health priority, and followed this up in 2002 with the publication of the World Report on Violence and Health, with in-depth discussions of intimate partner and sexual violence [5]. The efforts of international women's movements to effect this change are reflected in the Millennium Declaration, adopted in September 2000 by the General Assembly of the United Nations which recognised "the promotion of gender equality and empowerment of women" as one of the eight Millennium Development Goals and resolved to combat all forms of violence against women [5].

UNICEF [10] reveals that sexual violence and rape by an intimate partner is not considered a crime in most countries, and women in many societies do not consider forced sex as rape if they are married or cohabiting with the perpetrator. Violence is a consequence of gender power inequities, at both a societal and relationship level, and also serves to reproduce power inequities [11]. The assumption is that once a woman enters into a contract of marriage, the husband has the right to unlimited sexual access to his wife. Surveys in many countries have revealed that approximately 10 to $15 \%$ of women report being forced to have sex with their intimate partner [11,12].

Literature indicates that the idea of equality, respect of differences for women's needs and choices does not figure in the psyche of abusing men. They equate power and authority with their rights as men and they understand that it is women's responsibility to meet their demands without questioning [11] indicate that qualitative research has shown that the links between HIV/AIDS, gender inequity, and gender based violence lie in the patriarchal nature of society, and ideals of masculinity that are based on control of women. Additionally men might have multiple partners and control their sexual encounters.

\section{Problem statement"}

The problem statement of this study is derived from a participant's expression that was encapsulated in her verbatim responses outlined below. A woman admitted to trauma unit A of a particular hospital in the Vhembe district where this study has been conducted relates her experiences of sexual assault. "I am pushed on the bed and he starts assaulting me----pull my panty down--. Mm-- I am scared of HIV infection... He does not use condom mm---- he looks thin and coughing nowadays-aggressive---he always says, 'I don't care, forkof', what's that? Hmm?. She paused for a while with tears running on the cheeks and she busted to cry, I---I'm-told, ---Hmm-told, I have, --have AIDS---". The health workers at the unit indicated that they have offered Voluntary Counselling and testing (VCT) to the client since her major IPV experiences she has reported were sexual assault and psychological abuse.

The trauma unit A consults women clients who reportedly experience any form of abuse. As Lecturers responsible for accompaniment of nursing students to the clinical settings, researchers have since observed that sexual violence was the second common form of violence women experienced in their lives. Out of five victims who came for counselling in a week, three reported sexual violence to be their worst experiences. This raises the questions "What is the women's experience of sexual assault? Is sexual assault a risk factor to the transmission of HIV infection among women?" The overall objective of the study was to increase understanding of IPV experiences of sexual assault, its effect on the transmission of HIV infection by women admitted in Unit A of a particular hospital in the Vhembe District.

\section{Research methodology}

Research design: The research design of this study was qualitative, exploratory descriptive and contextual using a phenomenological approach [14]. The researcher intended to describe the experience of sexual assault as one of the risk factor of transmission of HIV infection among women admitted in the Trauma unit $\mathrm{A}$ at a particular hospital in the Limpopo Province.

\section{Population and sampling}

Population is referred to as the entire group of people that meet a designated set of criteria [14]. In this study the target population consisted of all women who made use of a trauma unit $\mathrm{A}$ ata particular hospital in the Limpopo Province. The unit admits three to five women per week who experience domestic violence and other forms of abuse. The participants were selected from clients who were still undergoing counselling sessions since patients were on short-term admission. Participants were selected by means of purposive sampling. Purposive sampling involves the conscious selection by the researcher of certain subjects to include in the study [14]. The researcher purposefully selected participants who had experienced IVP and reported sexual assault to be their worst experience, and had been admitted in the trauma unit $\mathrm{A}$. The unit comprised of 13 patients at the time of data collection. In this study six (6) women were interviewed. The sample size proved to be adequate when the researchers experienced redundancy in the participants' descriptions. Participants were interviewed until data saturation was reached as demonstrated by repetition of categories.

Let us include the number of women who were in the trauma unit at the time of the study.

\section{Data collection}

In-depth individual interviews were conducted, using unstructured interviews which were voice recorded. The participants were shown the voice recorder and the button to switch it off if the participant did not want certain information to be recorded during the interview. Furthermore the participants were assured that the recordings will be erased upon completion of the study. The interviews were conducted in their mother tongue, which is Tshivenda, to ensure that they are able to express their experiences well. The interviews lasted between 60-90 minutes. Participants sometimes cried during the interview and the researcher used facilitating communication techniques such as minimal responding, clarification and rephrasing to encourage the women to speak openly and freely about their experiences [15-17].

Follow-up interviews were conducted with three of the participants to validate the participants' frame of reference. Field-notes were written which described the researchers' observations and experiences during the interviews, and were kept in one of the researcher's office drawer under lock and key [18] for the period of the completion of the study.

Researchers arranged multiple visits with the participants to establish interpersonal relationships. Morgan and Thapar-Björkert [6] assert that when research is conducted on any sensitive issues such as domestic and sexual abuse, ethical issues are paramount. The researcher must be concerned about the safety of the participants. One central question was posed. "Please share with me your experience of sexual assault? Is sexual assault a risk factor to the transmission of HIV infection among women?".

\section{Data analysis}

In this study data analysis started during the data collection process 
Citation: Madzimbalale FC, Khoza LB, Lebese RT, Shilubane HN (2011) The Intimate Partner Violence experiences of sexual assault, a risk factor on the transmission of HIV infection among women in the Vhembe District of Limpopo Province, South Africa. J AIDS Clinic Res 2:130. doi:10.4172/2155-6113.1000130

Page 3 of 6

when interviews were conducted. Records were maintained and constantly reviewed. This view is supported by Streubert and Carpenter [19] who indicate that analysis of qualitative data is a hands-on process and that researchers must become deeply involved in the data. The process of data analysis took the form of clustering similar data to develop a theme and categories.

Tesch's data analysis principles were applied [18]. Tesch provides the following eight steps that are to be considered when analysing qualitative data: getting a sense of the whole; picking one interesting document; making a list of topics; clustering together similar topics; looking for the most descriptive wording; making the final decision; assembling data belonging together and recording existing data. Analysis was done by establishing the main theme, categories and subcategories to which text fragments were assigned.

\section{Ensuring trustworthiness}

The principles outlined by Lincoln and Guba [20] were followed to ensure the trustworthiness of the study. Credibility was achieved through spending time with each participant to gain her confidence. The participant was instructed to turn the tape recorder off if she felt uncomfortable being recorded. Participants were purposively sampled and, entering into the second session of interviewing women, prolonged the engagement, increased probing of information and enhanced data saturation. Tape recordings as well as field notes written during interviews increased the conformability of the research. Transferability was ensured by complete description of research method, in-depth discussions of the data obtained and interpretation of the research findings in the study report. In-depth literature control on the topic of the study and verbatim quotes cited in the findings will enable readers to do self-evaluation of their own experiences of sexual assault.

\section{Ethical considerations}

Permission to conduct the study was sought from higher degree committee of the School of Health and ethics committee at the University of Venda, the Limpopo Department of health and Social Development and the hospital management and trauma unit.

The participants were protected by maintaining the ethical standards such as sufficient information regarding participation was provided in the informed consent form; assurance of confidentiality and anonymity where even the researcher could not link the names of the participants with any information that was given to her; freedom from exploitation was ensured by the researchers' avoidance of abusing their privileged position and individual participants was regarded as autonomous being with the right to make choices without being coerced. The participants were also informed of their right to withdraw from the study at anytime without fear of being victimised [14]. The researchers as part of the health professionals established relationships with patients and provided emotional support before approaching them to request their participation. In a similar study conducted in the United Kingdom researchers used women who they had offered support and established relationships in the past year as participants [6].

\section{Experiences of sexual violence}

The participants experienced sexual violence, such as rape. According to the Domestic Violence Act No.116 of 1998 [7], sexual violence/abuse means any conduct that abuses, humiliates, degrades or otherwise violates the sexual integrity of the (complainant) woman.

\section{Results}

The biographical data describe that ages of the participants ranged from 32 to 54 and they were from wide range of educational, economic and social background. Two participants were holding matric certificates working as general labourers in the local shops. All the participants were Tshivenda speaking and two legally married under customary law whilst the remaining four were staying with boyfriends without legal bounds.

From the data that were collected the following categories and subcategories of violence emerged as experiences.

The five participants indicated that they were repeatedly raped by their intimate partners and as a result they were exposed to high risk of contracting sexually transmitted infections and HIV and AIDS. Among the participants, four indicated that they tested HIV positive and two have started Anti-retro viral (ARV) treatment. The other two expressed the concerns that although they might be testing HIV negative or positive, they were not mentally ready to seek HIV Counselling Testing (HCT). One participant was reluctant to use the name "rape" to describe how her partner engages to sexual acts. A participant said, "I am used to this rough handling, it happens every day when he wants to have sex with me". Through probing she explained that "he would hold my neck, rip my panty off while swearing at me that I am a prostitute". The participant was further asked to describe her understanding of the meaning of "rape". She laughed but showing unpleasant facial expression and roughly said, "Rape happens in the bush. Women are killed every day, stabbed by unknown men. Women report rape to the police to look for these criminals, but how can one report her husband----mm-is it easy to let him go to jail? You say---you say! I'm raped to public---, with my own husband? "Azwi iteyi ngo" meaning it is impossible".

The other three participants showed understanding of rape as follows:

"A man has no right to force me to have sex with him. It must come out of my interest. Even though I cannot initiate and ask for it-- laughing, "I will show him that I want to have sex with him. But, -- pause, my experience is related to rape". When probed about her experiences of rape she said, "Hhh you see these marks around the neck? He strangled me because I refused to have sex with him without a condom. I screamed for help, but instead my mother in law came out from her hut and swears at me that I am bringing curse in the family. I'm scared---mm, I don't sleep---, maybe I have AIDS--, hhi-testing? No! -- I am afraid".

"I know that what my husband is doing to me is rape and he might be arrested when I report to the police. He-infected me now-she pauses, he refuses to use a condom-her girlfriend died of AIDS related illness-yes, who does not know? People in the village talk about it---, they gossip around---, I know" Whipping and looking down silently. Before she was asked about her feelings regarding the disease, she said, "I have accepted that I am HIV positive, we receive education and a lot of support from nurses where I take my treatment...mm.. I come from poor family-I'm poor-m." Despite, she showed signs of

\begin{tabular}{|l|l|l|}
\hline Main theme & Categories & Sub-categories \\
$\begin{array}{l}\text { Experiences } \\
\text { of }\end{array}$ & $\begin{array}{l}\text { Sexual assault as a } \\
\text { risk }\end{array}$ & $\begin{array}{l}\text { Women experienced the conse- } \\
\text { quences of }\end{array}$ \\
lence & $\begin{array}{l}\text { factor to the transmis- } \\
\text { sion of } \\
\text { HIV infection }\end{array}$ & $\begin{array}{l}\text { sexual violence such as: } \\
-\quad \text { Rape and } \\
-\begin{array}{l}\text { Sexually transmittedln- } \\
\text { fections and HIVIAIDS }\end{array}\end{array}$ \\
\hline
\end{tabular}

Table 1: summary of theme and sub-categories regarding the experiences of sexual assault by women in Trauma Unit A of a particular hospital. 
Citation: Madzimbalale FC, Khoza LB, Lebese RT, Shilubane HN (2011) The Intimate Partner Violence experiences of sexual assault, a risk factor on the transmission of HIV infection among women in the Vhembe District of Limpopo Province, South Africa. J AIDS Clinic Res 2:130. doi:10.4172/2155-6113.1000130

courage and will power; she expressed a proverb that when translated from Tshivenda to English says that, "A woman's grave is in marriage". Rodrigo and Rajapakse [21] in their study found that poor women are disadvantaged with regard to HIV positive. They concluded that poverty increases vulnerability to HIV positive among women.

Another participant said, "One day my husband raped me because our sexual relationship had not been good and I had not been willing. I have sometimes been a quiescent partner, but there were times when I said 'No, I do not want to have sex now for this and that reasons' and he would just ignore what I said and go ahead with sex". When asked about the consequences of abusive sexual acts, she indicated that many women got HIV and sexually transmitted infections because of being raped. She pointed out other three relatives of hers who were in abusive relationships and died of AIDS. Her excerpts as "It was frightening to lose my two cousins and my sister in law die of AIDS. Who knows?" Pauses-"I might be infected as well". She further indicated that women experience consequences of abusive sexual acts, including stressful lives, post traumatic stress disorders, and leads them to commit suicide because they are helpless to liberate themselves from IPV experience.

One participant said, "I usually fight with my husband when it comes to sex because he does not want to use condoms and he has got a lot of girlfriends. I know some of his girlfriends; in such situation it is easy to contract HIV/AIDS and also sexually transmitted infections. I do not always win the fight we end up engaged in unprotected sex which is very dangerous to me." When asked whether she has visited HCT services before, she indicated that she started taking ARV treatment four years ago and that she has adjusted and accepted her condition. She further indicated that if her husband could stop abusing her and also go for HCT, she would live longer without continuous stress. "The only problem in my family is that I receive treatment alone. He is aware that he is sick, but saying that it is me who infected him. I have learnt a lot about the disease, I no longer fear it but I fear re-infection because he has many girl friends around, it becomes worse when he is drunk, he drinks a lot---."

Women with abusive partners are frequently unable to refuse sex with their partners or to negotiate any form of safer sex including monogamy, abstinence, or the use of condoms for fear of a violent response [22]. These groups of abusive men, who are often also promiscuous, pose a risk to their female partners who are thus denied the right to protect themselves against sexually transmitted infections including HIV. There are studies that have identified a series of individual level factors that are associated with an increased risk of sexual violence against women including alcohol abuse, which may trigger or predispose one to violence $[12,23,24]$.

Arries [25] indicates that people should treat and respect each other as human beings. This means that husbands or partners should demonstrate respect towards their wives or partners. To demonstrate respect is to demonstrate sensitivity to the differences in the views that people as human beings might hold and learn to understand them even if there are some disagreements. This implies that people should respect the autonomy of others. The finding is supported by Rasool [26] in his launching speech of a commission on Gender Equality. He indicated that there should be a move away from a model of masculinity that dictates to women. Women should be treated with kindness in a paradigm where women are treated as equals at all levels, from home to the work place. People need to take on the traditional values that prioritise men in order to move to a situation where women are truly equal at every level.
The finding of men not wanting to use condoms is supported by Sethosa and Peltzer [27]. They mention that most of the time men control sexual decisions, and therefore women are likely to report coercive sex with their partners. Men indicate that they do not like condoms therefore they are not going to use them. Women are also unable to discuss safer sex with their husbands or sexual partners because of gender imbalances in sexual decision making. This is a particular problem for married women who depend on their husbands for food, clothes, children's education and security [21].

The studies also reveal that unremedied domestic violence which is itself a widespread and chronic abuse of women all over the world plays a critical role in exposing women to sexually transmitted infections and HIV/AIDS. The fear of violence prevents women from negotiating condom use or refuse unwanted sex. The socialisation of women as being passive and men as being dominant, sets the stage for abuse of the women. Being passive may increases women's vulnerability to sexual abuse. Some women are not aware of their rights, such as freedom, security, and the possibility of a protection order, and this contributes to their being abused by their husbands $[5,22,28]$.

Literature confirms that an association between abuse and sexual risk behaviours, harmful traditional practices including having multiple sexual partners and the use of substances before sex, has been observed among young men. Some studies have found an association between abuse and recent adulthood sexual risk behaviours [29-31].

According to the constitution of the Republic of South Africa 1996 (Act 108 of1996) [8] section12 (2) (a), everyone has the right to bodily and psychological integrity which includes the right to make decisions concerning reproduction and security, and control over their body. A study carried by Boonzaier [32] on sexual violence in South Africa, supports the findings by indicating that within the SouthAfrican context marital sexual infidelity seems to be very common.

Sexual infidelity has also been described as a common feature of adolescent relationships and is associated with violence and coercion in these relationships. Relationship power and control by the male partner and infidelity in intimate relationships are also related to the high rates of HIV infection among South African women and the spread of the HIV/AIDS pandemic in South Africa. Ellsberg [5] reveals that a growing body of research indicates that violence may increase women's susceptibility to HIV infection. Studies carried out in Tanzania, Kenya and South Africa found that seropositive women were more likely than their seronegative peers to report a physical abuse. It is also suggested abusive men are more likely to have HIV and impose risky sexual practices on their partner [33].

\section{Limitations}

The study showed some limitations with respect to the generalisability of the findings. The women in the sample were obtained from a Trauma Unit A in a particular hospital in the Vhembe District. The choice to report was up to the women themselves. Therefore, the results are not generalisable to abused women in general. The women's means of coping was also not assessed. Future researchers should explore the physical and mental health symptoms experienced by women as a result of intimate partner violence.

\section{Recommendations}

Husbands together with their female partners experiencing IPV should be encouraged to attend workshops on sexually- transmitted infections and HIV/AIDS so that they can be aware of the danger of contracting such infections. Men will also learn that sex can be negotiated between husband and the wife and sexually-transmitted 
Citation: Madzimbalale FC, Khoza LB, Lebese RT, Shilubane HN (2011) The Intimate Partner Violence experiences of sexual assault, a risk factor on the transmission of HIV infection among women in the Vhembe District of Limpopo Province, South Africa. J AIDS Clinic Res 2:130. doi:10.4172/2155-6113.1000130

Page 5 of 6

infections, HIV/AIDS and unwanted pregnancy can be prevented by wearing a condom. Harmful traditional practices that subjugate women in marriage and subordinate them sexually to their husbands should be eradicated. Primary health care workers as providers of primary care to the community should realise the need for screening and prevention programmes that aims to reduce Intimate Partner Violence and HIV infection.

\section{Conclusions}

The observations in the study suggest that experiences of, sexual violence by a partner may be associated with increased physical injuries and increased Sexually transmitted Diseases and HIV and AIDS. The extent to which the associations between partner violence and reported ill health in women in the Vhembe District should be further investigated and documented. Rather than targeting this high-risk group in the context of sexual violence alone, HIV positive interventions might address a range of HIV risk behaviours that includes the nonnormative nature of both sexually and physically abusive behaviours [23].

\section{References}

1. Chan RL, Martin SL (2009) Physical And Sexual Violence And Subsequent Contraception Use Among Reproductive Aged Women. Contraception 80: 276 281.

2. Rose RC; House AS, Stepleman LM (2010) Intimate partner violence and its effects on the health of african american HIV-Positive women. Psychol Trauma 2: 311-317.

3. Sareen J, Pagura J, Grant B (2009) Is intimate partner violence associated with HIV infection among women in the United States? Gen Hosp Psychiatry 31: $274-278$

4. Ulibarri MD, Strathdee SA, Lozada R, Magis-Rodriguez $\mathrm{C}$, Amaro $\mathrm{H}$, et al (2010) Intimate partner violence among female sex workers in two mexico-U.S. border cities: partner characteristics and HIV risk behaviours as correlates of abuse. Psychol Trauma 2: 318-325.

5. Ellsberg M (2006) Violence against women and the millennium development goals: facilitating women's access to support. Int J Gynaecol Obstet 94: 325332.

6. Morgan K, Thapar-Björkert ST (2006) l'd rather you'd lay me on the floor and start kicking me': understanding symbolic violence in everyday life. Women's Studies International Forum 29: 441-452.

7. The Domestic Violence Act (1998) (Act No. 116 of 1998) South Africa: Department of Justice.

8. The Constitution of The Republic of South Africa (1996) (Act No.108 of 1996). South Africa: Juta Law Publishers.

9. Goosen M, Klugman B (1996) The South African Women's Health Book. Cape Town: Oxford University Press.

10. United Nations Children's Fund (UNICEF) (2000) Domestic violence against women and girls. Innocenti Digest No.6 June 2000

11. Jewkes R, Dunkle K, Nduna M, Shai N (2010) Intimate partner violence, relationship power inequity, and incidence of HIV infection in young women in South Africa: A Cohort Study. The Lancet 376: 41-48.

12. Sawyer-Kurian KM Wechsberg WM, Luseno WK (2009) Exploring The Differences And Similarities Between Black/African And Coloured Men Regarding Violence Against Women, Substance Abuse, And HIV Risks In Cape Town, South Africa. Psychology of Men and Masculinity 10: 13-29.

13. Celbiş O, Gökdoğan MR, Kaya M, Günes G (2006) Review of forensic assessments of female referrals to the branch of legal medicine, Malatya region , Turkey - 1996-2000. J Clin Forensic Med13: 21-25.

14. Burns N (2009) Thepractice of nursing research: appraisal, synthesis and generation of evidence. 6thedition. St. Louis: Saunders.

15. Babbie E, Mouton J (2002) The Practice Of Social Research. USA: Oxford University Press.
16. De Vos AS, Strydom H, Fouche CB, Delport CSL (2007) Research at grassroots: For the social sciences and human service professions. 2nd edition. Pretoria: JL Van Schaik.

17. Minichielo V, Aroni R, Timewell E, Alexander L (1991) In-depth interviewing researching people. Melborne: Longman Cheshire.

18. Creswell JW (2009) Research design: Qualitative, quantitative and mixed methods approach. Los Angeles: Sage.

19. Streubert HJ, Carpenter DR (1999) Qualitative research in nursing. Advancing the humanist imperative. Philadelphia: JH Lippincott Company.

20. Lincoln YS, Guba EG (1985) Understanding and doing naturalist inquiry SAGE: Publication, Inc.

21. Rodrigo C, Rajapakse S (2010) HIV, poverty and women. International Health 2: 9-16.

22. Fustos K (2011) Gender-based violence increases risk of HIV/Aids For women in sub-Saharan Africa. Population Bureau.

23. Go VF, Srikrishnan AK, Salter ML, Mehta S, Johnson SC, et al. (2010) Factors associated with the perpetration of sexual violence among wine-shop patrons in Chennai, India. Soc Sci Med 71: 1277-1284.

24. Zablotska IB, Gray RH, Koenig MA, Serwadda D, Nalugoda F, et al. (2009) Alcohol use, intimate partner violence, sexual coercion and hiv among women aged 15-24 in Rakai, Uganda. AIDS Behav 13: 225-233.

25. Arries E (2005) Virtue ethics: An approach to moral dilemmas in nursing Curationis 28: 64-72

26. Rasool E (2005) Reducing Violence Means Tackling Patriarchy. Bua News: Tshwane.

27. Sethosa E, Peltzer K (2005) Evaluation of HIV Counselling and testing, selfdisclosure, social support and sexual behaviour change among a rural sample of HIV reactive patients in South Africa. Curationis 28: 24-41.

28. Tsang JA, Stanford MS (2007) Forgiveness for intimate partner violence: The influence of victim and offender variables. Personality and Individual Differences 42: 653-664.

29. Foluso AF (2011) Gender based sexual violence among Nigerian widows: Implication for HIV transmission. Current Research Journal of Social Sciences 3: 139-145.

30. Littleton H, Breitkopf CR, Berenson A (2007) Sexual and physical abuse history and adult sexual risk behaviours: Relationships among women and potential mediators. Child Abuse Negl 31: 757-768.

31. Wenzel SL, Tucker JS, Elliot MN, Marshall GN, Williamson SL (2004) Physica violence against impoverished women. A longitudinal analysis of risk and protective factors. Womens Health Issues 14: 144-154.

32. Boonzaier K (2005) Women abuse in South Africa: A brief contextual analysis Feminism and Psychology 15: 47.

33. Prabhu M, Mchome B, Ostermann J, Itemba D, Njau B, et al. (2011) Prevalence and correlates of intimate partner violence among women attending HIV voluntary counselling and testing in Northern Tanzania, 2005-2008. Int J Gynecol Obstet113: 63-67. 